\title{
Leadership Gap in Agile Teams: How Teams and Scrum Masters Mature
}

\author{
Simone V. Spiegler ${ }^{1,2(\bowtie)}$, Christoph Heinecke ${ }^{2}$, and Stefan Wagner ${ }^{1}$ \\ 1 Institute of Software Technology, University of Stuttgart, Stuttgart, Germany \\ \{simone.spiegler, stefan. wagner\}@iste.uni-stuttgart.de \\ 2 Robert Bosch Automotive Steering GmbH, Schwäbisch Gmünd, Germany \\ Christoph.Heinecke@bosch.com
}

\begin{abstract}
Motivation: How immature teams can become agile is a question that puzzles practitioners and researchers alike. Scrum is one method that supports agile working. Empirical research on the Scrum Master role remains scarce and reveals contradicting results. While the Scrum Master role is often centred on one person in rather immature teams, the role is expected to be shared among multiple members in mature teams. Objective: Therefore, we aim to understand how the Scrum Master role changes while the team matures.

Method: We applied Grounded Theory and conducted qualitative interviews with 53 practitioners of 29 software and non-software project teams from Robert Bosch GmbH.

Results: We discovered that Scrum Masters initially play nine leadership roles: Method Champion, Disciplinizer on Equal Terms, Coach, Change Agent, Helicopter, Moderator, Networker, Knowledge Enabler and Protector. They transfer some of those roles to the team while it matures. The Scrum Master provides a leadership gap, which allows team members to take on a leadership role.

Conclusion: The Scrum Master role changes while the team matures. Trust and freedom to take over a leadership role in teams are essential enablers. Our results support practitioners in implementing agile teams in established companies.
\end{abstract}

Keywords: Agile teams $\cdot$ Scrum Master role $\cdot$ Maturity

\section{Introduction}

Recently, more and more organisations implement agile teams. Yet, it is not entirely clear how to become agile. At present, a very popular agile approach is Scrum [21]. Scrum proposes the role of the Scrum Master who takes on a team leadership role [18]. The Scrum Master is considered to be a facilitator of the Scrum process and enables a team to work in a self-organised and crossfunctional way. Furthermore, the Scrum Master protects the team from external disruptions [21]. 
Yet, empirical research on Scrum teams found that the Scrum Master sometimes acts as a barrier to teams becoming agile in early stages. The reason is that Scrum Masters tend to stick to a command-and-control mode [18]. In contrast, teams applying agile methods for three years on average appear not to struggle with the Scrum Master and are even supposed to share the leadership role [20].

These diverging results could be explained by changes in the maturity of agile teams. A team learns how to be agile while undergoing different maturity stages [12]. Hence, agility of a team is a process that unfolds over time [24]. Yet, to the best of our knowledge, there is no empirical analysis of the changing leadership role of the Scrum Master during the agile journey.

To be able to support organisations in the agile transformation, our research objective is to explore the Scrum Master role and how the role changes while the team matures. We believe investigating the changing leadership role of the Scrum Master will provide valuable insights into how teams can become agile.

We collected data in 11 business divisions of the conglomerate Robert Bosch $\mathrm{GmbH}$, primarily operating in the automotive industry. We applied Grounded Theory [10] and conduced qualitative semi-structured interviews with 53 Scrum practitioners from 29 different software and non-software project teams that had applied Scrum over a period of three months up to three years.

We help practitioners in understanding how the Scrum Master can enable a team to become agile in an established company by providing empirical insights on the agile transformation at Robert Bosch GmbH. Applying Role Theory $[1,14]$, the 53 interviews revealed that Scrum Masters incorporate nine different roles which they transfer to the team while it matures. We further introduce the concept of a leadership gap into research on agile teams which enables team members to take on a leadership role themselves. Hence, we conclude that the Scrum Master role changes while the team matures.

\section{Related Work}

Several authors describe agile teams as being empowered to work in a selforganised and cross-functional manner and that those teams continuously learn and adapt to changing conditions [5,23]. Cross-functionality implies to understand each other's roles and domains within one team and to be able to work with each other due to a shared understanding [14]. Self-organisation indicates that teams enjoy a high level of freedom considering how to do their work [4]. It is no longer the supervisor who assigns tasks to individuals but the team members themselves assign tasks to themselves [4]. If Scrum teams are led by command-and-control, e.g. members cannot chose their tasks, agility will not materialise [7,14].

Empirical research on the concept of a Scrum Master shows conflicting results regarding the Scrum Master behaviour. Moe et al. [18] find that team members rarely take over responsibility, while Srivastava and Jain [20] arrive at the conclusion that all team members should be able to take on the Scrum Master role. Moe et al. [18] observed the implementation of agile methods within one 
Scrum team over a period of 9 months. They found that the Product Owner and the Scrum Master tend to take over a leadership role most of the time. They describe how a Scrum Master posed a barrier to self-organisation: The person started to control team members which made them stop revealing their impediments and, as a consequence, resulted in weak team leadership and lack of trust. The authors also describe, however, that team leadership improved over time in such a way that more and more team members took over responsibility. Srivastava and Jain [20], who investigated teams that had been working in an agile way for three years on average, outline that the aim of an agile team is to lead themselves. However, they refer to Carson et al. [2] and acknowledge that taking over responsibility in a Scrum team is a process that unfolds over time due to a shared purpose, social support and voice.

How to evolve from an immature team to a mature one and which role the Scrum Master plays in this journey is yet not clear. We have not found any empirical study on the Scrum Master that specifically examines how the Scrum Master role changes while the team matures.

Cockburn [3] refers to the Japanese philosophy of Shu-Ha-Ri and describes Scrum as a maturity model for agile adaption. Likewise, Gren et al. [12] state that depending on the maturity level of a team, team members practice agile work differently. In the introduction of his doctoral research, Gren [11] suggests that leadership should adapt to different maturity stages of agile teams. He refers to Situational Leadership Theory $[13,17]$ and claims that leaders of agile teams need to demonstrate more monitoring at an early stage but can delegate tasks at a later stage of team development. Hoda et al. [16] examine both mature and immature teams and discover six different self-organising roles. They claim that roles can be transferred from formal role keepers in rather immature teams to any team member with the right set of skills in more mature teams.

Since the Scrum Master role has been shown to either display commandand-control behaviour of one formal role keeper in an immature team [18] or has been suggested to be played by multiple group members in mature teams [20], we believe that the Scrum Master role can be transferred from one individual to distinct team members while the team matures. Yet, this transfer has not been empirically investigated.

\section{Study Design}

\subsection{Research Question}

Our research objective is to understand the changing leadership role of the Scrum Master in an agile team over time.

RQ1: Which roles does the Scrum Master play in an agile team?

RQ2: In which way do team members take on the Scrum Master role over time? RQ3: How are roles transferred from the Scrum Master to the team members? 


\subsection{Context and Subject Selection}

We chose Grounded Theory because this method is applied in research fields with scarce knowledge and it aims at generating new theory on social interaction between actors [10]. Furthermore, this method increasingly gains popularity among researchers to investigate human aspects of agile working [15]. Since it is an interpretative approach the research question should be embedded in the specific context under study [10].

We conducted this study at Robert Bosch GmbH. The Robert Bosch GmbH employs more than 410,000 people in 60 different countries worldwide. The company history dates back to 1886 and can therefore be classified as an established company. The conglomerate is active in four different business areas: mobility solutions, industrial technology, consumer goods as well as energy and building technology. Each business area consists of various subsidiaries and business divisions. Therefore, market conditions and subcultures vary wildly.

While the agile transformation used to be a central project, now each division is responsible for its own agile transformation. Even though there exist a role description for a Scrum Master behaviour, there is neither an obligatory training nor a general rule regarding the Scrum Master. Each team can decide on its own how to train the team and Scrum Masters in the agile way of working. For example, they could book a training internally or externally of the company or not book a training at all.

Two authors have direct access to the field. We collected data on the topic between June 2017 and November 2018. We identified Scrum practitioners either via our personal network or via intranet and first contacted them by email. We conducted interviews according to availability and willingness to take part.

We collected data from 11 business divisions which have slightly different subcultures. Most divisions were active in the automotive industry, while others produced domestic appliances and gardening tools. Interviewed teams stated that they apply the method Scrum mostly in modified form, e.g. w.r.t. the regularity of Scrum meetings. All Scrum Masters were without disciplinary power, responsible for the Scrum process and in charge of team development. Most practitioners of the company call the Scrum Master role Agile Master, indicating that this role should adapt to the specific team, rather than sticking to the Scrum approach by the book. Thus, we consider the sample fitting to examine maturity and the changing Scrum Master role.

In total, our data includes 22 Scrum Masters, 8 Product Owners and 23 team members from 14 software development and 15 non-software project teams. The size of teams ranged from 5 to 12 members and often included diverse nationalities. Since the age of teams stretched from three months up to three years, we expected the maturity of teams to vary. To respect participants' confidentiality, we cite them by SM (Scrum Master), TM (team member) and PO (Product Owner). 


\subsection{Data Collection and Analysis Procedure}

The research problem should be allowed to emerge during the study while collecting data at the research field [10]. We observed Scrum events, such as the daily stand-up, review, planning and retro, of various agile teams and conducted three rounds of qualitative interviews. To identify a focus topic, the authors first conducted unstructured interviews with practitioners to discover which focus topic related to leadership in agile teams would be interesting to be explored. The interviews revealed that Scrum Masters struggled with empowering the team for self-organisation, while some practitioners also reported that self-organisation of agile teams improved over time.

In a follow-up study we conducted semi-structured face-to-face interviews of $45 \mathrm{~min}$ on average. Interviewees were asked about their personal experiences on agile projects with a focus on the Scrum Master role and what they had learned since they had started to apply the Scrum method. The guiding questions are available online [19].

Interviews were audio-taped and transcribed. We coded the collected data by applying Glaser's Grounded Theory [10]. We openly coded transcripts sentenceby-sentence and aligned codes that appeared to be alike to one concept. We constantly reflected those concepts critically. We aligned concepts if they appeared to be alike to build categories [10].

We identified multiple activities (concepts) the Scrum Masters claimed to do to support the Scrum teams and further aligned the different activities to nine roles (categories).

One bundle of concepts described one category. For example the category change agent contained the concepts serving as a role model, changing habits, and convincing project teams of the agile way of working.

Grounded Theory follows an iterative approach in which each step determines the next step to be taken during the research [10]. Previous interviews had revealed that the Scrum Master role had changed over time and that team members started to take over more responsibility. Drawing on theoretical sampling [10], we conducted a third round of interviews where we approached the Scrum Master role additionally from the team's perspective and addressed teams as a whole. This showed that team members of rather mature teams also had learned to play some of the Scrum Master roles.

Additionally, Scrum Masters explained that they gradually lead the team less and also that sometimes they would empower the team by doing nothing at all, which we labelled leadership gap. Through constant comparison [10] of various interviews and observations we identified nine different Scrum Master roles and developed a substantive theory [10] which we labelled the role transfer process.

\subsection{Validity Procedure}

At the beginning of each interview, participants were informed about the purpose of this study and assured of confidentiality, so as to receive open and honest responses. 
The majority of participants spoke openly, also about their personal concerns what was not working well in their organisation or in their agile team. There were three people from three different teams whose overly positive statements did not match with the comments on the same topic from other interviewees of the very same team. Since the authors could not be sure whether social response bias applied or the interviewees were really overly positive people, those three participants were excluded from the sample.

\section{Results}

Our first two research questions aimed at understanding which roles the Scrum Master plays in an agile team (RQ1) and in which way team members take on the Scrum Master role over time (RQ2).

We identified a set of nine different roles that Scrum Masters played. While some teams reported that the leadership roles were rather centred on the Scrum Master, other teams revealed that the Scrum Master role had changed over time. In the latter cases, team members started to take over some of the roles themselves and the Scrum Masters reduced the extent to which they played those roles. In the following Sect. 4.1 we will describe the nine Scrum Master roles. Each role description is divided into three parts:

1. Description of the role in general (RQ1)

2. How the Scrum Master played that role (RQ1)

3. How team members took over that role after some time (RQ2).

\subsection{Nine Scrum Master Roles}

Role 1: Method Champion. Organises meetings and get-togethers, teaches the method, supports formulating tasks and setting goals, visualises information, and discusses how to adapt the method during the retrospective.

Scrum Master: A large majority of Scrum Masters mentioned the method to be their main task when working with agile teams. Many emphasised that they continuously helped the team to adapt the method to their specific context.

Team: In newly established agile teams, members rather waited until the Daily Stand-Up to speak about issues with each other. Over time, teams started to speak with each other right away when an issue occurred. Some teams stated that the Scrum Master had initially organised team events but after some time the team members organised such events themselves. Also, two teams explicitly stated that their team visualised information on a board on their own initiative and that this was the way they learned and exchanged knowledge.

Role 2: Disciplinizer on Equal Terms. Supports the team to keep to the rules, ensures that the team focuses on relevant topics and makes sure that team members attend the meetings. Discipline is accomplished via communication on a par. Interaction on equal terms creates non-hierarchical spaces which are important to speak openly with each other. 
Scrum Master: Initially, some team members were reluctant to follow the Scrum process. When the Scrum Master insisted on discipline, however, such as only talking for a certain amount of time during the daily or to follow up on measurements they had agreed on during the retrospective, the team members started to see the benefit. It is important to note that discipline was described to focus on the Scrum process, not on direct control of team members. If individuals were controlled directly, they reported to loose sense of responsibility.

Team: Over time, team members learned to focus and prioritise their own work. For example, team members reported to only do one thing at a time and not everything at the same time as they used to do in the past, or they stopped their peers from endless discussions.

Role 3: Coach. Observes team members and uncovers which kind of behaviour is missing in a team to improve teamwork, provides feedback, and helps teams to find out what they wish to change and how to do so.

Scrum Master: Scrum Masters reported to initiate team-building activities, brought developing conflicts to the surface and helped the team to solve them. Coaching was considered important to foster teamwork and self-organisation.

Team: Several interviewees described how the Scrum Master built trust among team members, e.g. during the retrospective. After some time they established psychological safety [9] and started to open up and to provide feedback to each other. It was no longer merely the Scrum Master who provided feedback to the team.

The retrospectives [...] push us to actually stand up for some opinion, to say what is wrong or to open up, and then he [the Scrum Master] unleashed the monster. I have always been very critical about lots of stuff, but now I see that everyone is critical sometimes, now I see that they [the other team members] actually care to say "look, I am not happy about this" and speaking openly had never happened before. (TM)

Role 4: Change Agent. Serves as a role model, changes habits, and convinces newly established project teams of the agile way of working.

Scrum Master: While a large majority helped team members get used to the method step by step, others wanted to help people develop a certain mindset, such as not being afraid of failure or openness towards results. Either way, their overall aim was to convince individuals why the agile way of working made sense.

At the beginning, it was a bit tough to convince some team members of the agile approach. But now I think our team does not want to work in a different style anymore. There is a drive in our team that some team members even would like to go further. They have been infected with the agile virus and they want more and more. (SM) 
Team: We did not come across a team members who started to act as a Change Agent pro-actively, such as convincing others of the method. However, several agile teams started to serve as role models for other teams by being agile. The Change Agent role might be important at the beginning of a newly established team. But while the team matures, this role might become obsolete.

Back then when I started with agile development, it was rather amusing. Because we felt like animals in a circus. At first, there was astonishment, then amusement, later interest and, finally, they asked whether they [our partner team] couldn't do it the same way. But this was not a process of a few days. It rather took several months. (PO)

Role 5: Helicopter. Possesses the ability to see the bigger picture, to know who possess the right skill for a certain task, to include relevant stakeholders and to structure work.

They identified cross-boundary links between individuals and tasks from different technical expertise or domains towards a common goal.

In our team, I don't feel like I am the boss or anything of that kind. I am just the one in my team who is best at keeping track of things and to give them a general direction. (SM)

Team: Due to regular communication and visualisation, team members developed a shared understanding $[14,18]$ while they matured, so that they were aware of who had certain knowledge or skills. Developing a Helicopter perspective helped team members to think in networks, to serve as sparring partners for each other and to be fast in handing over the work to another professional of another expertise.

In the beginning, I think you don't know who has more experience in a certain area or expertise in another area. But slowly I get to know everyone and can judge who can support me in which difficulty in the quickest possible way. [...] But in the end I know, okay, I have a problem here and who can support me. (TM)

Role 6: Moderator. Moderates all kind of meetings and builds a bridge between perspectives and domains. This role is considered to be important to develop the necessary cross-functional understanding for agile teamwork.

Scrum Master: They mediated between individuals from different domains and helped the team to build a shared understanding and to tolerate each other.

Team member: No interviewee elaborated on a situation in which a member played the Moderator successfully. One team reported that they had tried letting team members lead the retrospective but it had ended up in a planning instead. Two teams felt that the Scrum Master should be the Moderator since they considered it to be difficult to remain neutral during a discussion when being part of the team. 
Role 7: Networker. Connects the team with relevant stakeholders, e.g. managers and experts, from within and outside the organisation.

Scrum Master: The way in which Scrum Masters used their network depended on the current need of the team. Scrum Masters reported that they included formal leaders to gain the support for the agile approach. Another Scrum Master reported how he had invited an expert for a certain method to train the team. Yet another Scrum Master stated that he knew colleagues from facility management whom he could call whenever the team needed organisational support.

You don't have to be better at designing than a design engineer. But you have to somehow show him ways to solve his problems. And if it is only by referring him to another design engineer. (SM)

Team: The Scrum Master provided contacts and empowered the team members to build their own network over time. This increased their scope of action and enabled them to quickly react to challenges.

For example, that one has an information for someone, that he normally would not have access to as a planning guy. [...] Actually, I bring in my network from production and the developer his network and the TEF person yet another. During the open discussion at the Daily Stand-Up, I can say that I have a problem. Someone knows someone who can help me with it. (TM)

Role 8: Knowledge Enabler. Realises which kind of knowledge the team needs, e.g. expert information or methodological skills, and supports team members to acquire that knowledge, e.g. sends them to training or conferences, and schedules knowledge exchange meetings. Furthermore, this role promotes iterative learning, e.g. learning from mistakes, and fosters learning-by-doing.

Scrum Master: Some Scrum Masters urged teams to take time for learning. A few of them convinced managers that agile teams must sit close to each other to approach each other easily, learn from each other and build a shared understanding.

They just do not know the whole approach and how to access it. They know classic learning like you go to a training or you study a book, but in this field, you have so many user groups, meet-ups [...]. And we also try to just propose a nice event. They can meet other people there and discuss with them. For example, we all went to a conference together. (SM)

Team: While some team members expected the Scrum Master to have the technical expertise to provide feedback, other interviewees had learned to receive feedback from their peers. They shared their progress and served as a sparring partner to each other. They also reported to just walk over to colleagues and ask for information, sit together when they had questions or collaborate on tasks. 
Today it is all very easy going. I just go over to my colleague's desk, sit down for, like, 45 min and work with him on a topic. Nobody says anything against that. It is very informal, but it also happens that I personally have to answer some questions. (TM)

Role 9: Protector. Shelters teams from inappropriate requests from the Product Owner, managers, disciplinary leaders and other departments.

Scrum Master: Scrum Masters reported protecting the team from re-prioritisation or too high workload by the Product Owner. Furthermore, they sheltered the team from management intervening in daily business or overruling decisions the team had come up with.

But then, I also pushed some things through in certain teams, [...] in which managers had taken decisions again. I had to go to the management and tell them "that is not OK, you make a mistake". Then they had to compromise and later they were really glad that they had reacted that way. Because the team gave the right hints after all. That is a situation in which one has to fight a battle on behalf of the team. (SM)

Team: One team implemented a role called "Batman" that was responsible for the protection from external requests that were unrelated to the respective sprint goal. The role keeper changed depending on day and time. Two teams reported that they struggled because the Scrum Master currently had no time to stick with the team regularly. One team stated that it had happened twice that management removed members temporarily during the absence of the Product Owner. The Product Owner wished that there was a Scrum Master on a regular basis to defend the team. Likewise, a Product Owner of another team said that he struggled with not intervening in operational work and tended to tell people what to do. He wished that there was a Scrum Master regularly to stop him from disturbing. Thus, we suggest that it might be difficult for teams to protect each other from management in an established company.

Investigating which role the Scrum Master plays (RQ1) and in which way it changes over time (RQ2), we found that the Scrum Master played nine different roles which he transferred to the team while it matured. In addition, we found that some roles were more suitable for a transfer to the team members than others. In the following, we will elaborate on how roles were transferred from the Scrum Master to the team members.

\subsection{The Role Transfer Process}

Our third research question was: How are roles transferred from the Scrum Master to the team members? We found that roles were transferred via three steps we labelled the role transfer process (shown in Fig. 1). Before we elaborate on the role transfer process in depth, we exemplify the concept by referring to the following story: 
When asked how he had learned to take over responsibility, one team member said that he had faced a major challenge in an area in which he had no previous experience. He had encountered a lack of leadership since no expert was there to support him. He said that, initially, he was afraid of taking over the responsibility necessary to tackle the challenge. Yet, he was left alone and had to solve the challenge himself. He had felt a sense of personal responsibility. Consequently, he had decided to take over a leading role. He felt a high level of self-efficacy after he had solved the challenge successfully and became a very proactive team member afterwards. He stated that in his current project, he missed such a lack of leadership and that he had observed that team members were reluctant to self-assign tasks. We name this lack of leadership which provides the opportunity for a team to take on a leadership role the leadership gap.

\begin{tabular}{|l|l|l|}
\hline Scrum Master & demonstrate role & leadership gap \\
\hline Team Member & support if needed \\
\hline observe role & claim and grant role $\sum$ play role \\
\hline
\end{tabular}

Fig. 1. The three steps of the role transfer process.

\section{We found that the role transfer process consists of three steps:}

The first step describes how the Scrum Master serves as a role model by performing all nine roles. The Scrum Master demonstrates how to perform the activities of the roles, while team members observe and communicate regularly on the meaning of the roles, e.g. with the help of visualisation. They build a shared understanding concerning the Scrum Master role which leads to role clarity.

If you want to do Scrum, you have to make sure that people understand the different roles. (SM)

The second step describes that Scrum Masters stop playing certain roles themselves after some time and simultaneously prevent management and Product Owners from taking on the respective role. While some teams stated that management allowed them to actually decide, others experienced that management, Scrum Masters or Product Owners were reluctant to hand over power and, consequently, team members did not take over leadership roles. Contrarily, team members who face a leadership gap in which no one plays the specific role get the opportunity to take on the roles themselves. If a team member claims the leadership role for him- or herself, other team members allow the respective team member to take over that role and accept the new role keeper.

As a Scrum Master I can provide strong support at the beginning to get started. But then I have to retreat gradually so that the team gets into the mode of self-organisation. Because if you do not create some free space or a vacuum, nobody will jump in. (SM) 
I try to help colleagues to find their way into the roles. It is always tricky to keep the balance between what the team should do by themselves and what should be done by the PO or SM. That is one thing that one has to reflect upon and to level out. [...] The most exciting thing is to bear the silence until someone says something and to wait until someone else gets active. [...] Also we have to give them some free space to experiment and try out themselves. (SM)

Scrum Masters stated that they either provided a leadership gap on purpose by not playing certain roles but waiting that team members would take on the opportunity and play the role, or they were not playing the role because they were absent which gave the team the chance to perform the role.

I did not have sufficient capacity to do everything myself. Therefore, some team members took over tasks, e.g. one guy arranged a timer, another one took care of the whiteboard. They were quite proactive as a team. [..] They did not tell me: "You are in the Scrum Master role, you have to make things better for us." (SM)

The third step describes that team members play most of the roles while the Scrum Master only continues to perform a role when still needed. The Moderator and Protector roles were found to be difficult to be transferred to the team, e.g. because the role keeper should remain unbiased. This indicates that the Scrum Master role does not become obsolete but is played to a lesser extent by a formally appointed person over time. Therefore, we suggest that some roles should always be played by the Scrum Master, which is a similar result as the findings by Hoda et al. [16] who discovered that in the absence of specific formal role keepers some aspects of agile working lost the team's attention, such as the retrospective.

It takes a lot of energy but is quite nice to experience when the team gradually walks by itself. At the same time, the time effort by the Scrum Master can be reduced. (AM)

Answering our third (RQ3) we found that a leadership gap enabled roles to be transferred from the Scrum Master to team members during the role transfer process.

\section{Discussion and Relation to Existing Evidence}

Our research objective was to explore how the Scrum Master role changes while the team matures. We discovered that the Scrum Master comprises nine leadership roles. While the team matures, more and more roles are transferred from the Scrum Master to the team. At the heart of the role transfer process lies the leadership gap: a lack of leadership which provides the opportunity for team members to step up and take on leadership roles which were previously filled by the Scrum Master. 
Several authors found that interference from Scrum Masters, Product Owners or management decreased self-organisation of teams $[7,14,18]$, while communication among team members improved when the Scrum Master was absent [18]. We believe that our finding of providing a leadership gap that allows teams to take over leadership roles fits well with those earlier observations.

Furthermore, the Scrum process, e.g. retrospectives, stimulates psychologocial safety $[6,9,14]$ which empowers team members to take on leadership roles. In line with other researchers our research provides empirical evidence that human interaction and the method go hand in hand [6]. Based on our results, we argue that the Scrum method combined with a certain behaviour, such as communication on equal terms, fosters a supportive team environment, such as mutual understanding and trust [18]. This empowers teams to take on leadership roles while they mature.

\section{Practical Implications}

Many practitioners on the management level have set the agile transformation of their organisations as one of their top priorities. This is often associated with the common misconception that when implementing agile projects their teams are instantly "doing twice the work in half the time" as the famous title of the book on the Scrum method promises [22]. Few have understood and accepted the time required for the team development process.

When agile teams are implemented in established companies, individuals have to learn a new way of leadership in teams, which will lead to slower delivery of work products at the beginning. Management should grant sufficient time to teams to allow them to regularly reflect upon the leadership roles during the retrospective, learn their meaning and content, build a mutual understanding and figure out how and to what extent to take on leadership roles. Teams need time to try the roles and learn them, possibly by failure. Just like any newbie in a formal leadership position needs time and is given time to learn the role, agile teams need time to learn the leadership roles of Scrum.

Furthermore, even though management expects employees to change and take on more responsibility, some managers are reluctant to grant leadership roles to the teams. External pressure, top-down changed targets and shifted priorities as well as frequent changes of the team setup destroy the sheltered space within which agile teams can grow. In established companies, it is easy to re-staff project teams because authorities have the legitimate power to do so, but it is a supreme discipline to protect the team and create hierarchy-free space for team development by the Scrum Master demonstrating lateral leadership.

Therefore, management must provide a Scrum Master to protect the team and shelter it while it matures. The Scrum Master has to be granted sufficient managerial power to protect the team and to preserve the leadership gap as a major enabler for the team's transformation. Simultaneously, the Scrum Master must be patient and wait until team members take on responsibility when they face a lack of leadership. Likewise, team members have to learn how to practice new ways of interacting with their team and managers, and to develop the 
courage to bridge the leadership gap when provided, even though it might feel inconvenient at the beginning.

\section{Limitations and Future Work}

To assure the quality of our research, we critically discuss construct validity, external validity and reliability:

To increase construct validity, we used multiple sources of evidence by capturing the Scrum Master role from three different angles involving Scrum Masters, Product Owners and team members. The researchers discussed the extracted results and built concepts and theories. Additionally, emerging results were frequently reflected critically with various agile practitioners from the company. Furthermore, the main author observed multiple agile teams at the company site over a period of 1.5 years. The final results were supported by the observations and fruitful discussions with practitioners.

All participants work at the same conglomerate, mostly in the automotive industry. To increase external validity, we tried to ask an equal number of project teams at each division. Despite their slightly similar overall working culture, the 11 business divisions embrace different subcultures. Still, we do not claim our results to be universally applicable and they might be limited to the specific context. Further studies should compare our findings on the changing Scrum Master role with the results emerging from other conglomerates.

Reliability: Since we used an open-ended semi-structured questionnaire that guided us through the interviews, the different interviews followed a similar structure. Yet, we asked participants about past events and what they had learned over time. Memories of individuals tend to change in retrospective. Therefore, these interviews are difficult to replicate. A cross-sectional follow-up survey on a nominal scale containing the nine roles with the respective activities we have identified would increase the reliability of this study.

So far we have only investigated how the Scrum Master role changed over time using an exploratory approach based on retrospective narratives of interviewees. We have not yet quantitatively aligned group maturity stages to the changing Scrum Master role. In a future research project, we aim to map research on maturity of agile teams [12] to the different Scrum Master roles we have identified to provide valuable insights on maturity and the changing Scrum Master role in each team development stage.

Furthermore, we have not yet captured the perspective of the management who may experience providing the leadership gap differently. Taking this aspect into account, we would like to extend this study in the near future and dig deeper into strategies on how the Scrum Master protects the leadership gap from management and Product Owner by referring to the boundary-spanning role of team leadership literature [8]. 


\section{References}

1. Belbin, R.M.: Team Roles at Work. Routledge, Abingdon (2012)

2. Carson, J.B., Tesluk, P.E., Marrone, J.A.: Shared leadership in teams: an investigation of antecedent conditions and performance. Acad. Manage. J. 50(5), 1217-1234 (2007)

3. Cockburn, A.: Agile Software Development, vol. 177. Addison-Wesley Boston, Boston (2002)

4. Cockburn, A., Highsmith, J.: Agile software development, the people factor. Computer 34(11), 131-133 (2001)

5. Conboy, K.: Agility from first principles: reconstructing the concept of agility in information systems development. Inf. Syst. Res. 20(3), 329-354 (2009)

6. Dingsøyr, T., Fægri, T.E., Dybå, T., Haugset, B., Lindsjørn, Y.: Team performance in software development: research results versus agile principles. IEEE Softw. 33(4), 106-110 (2016)

7. Drury, M., Conboy, K., Power, K.: Obstacles to decision making in agile software development teams. J. Syst. Softw. 85(6), 1239-1254 (2012)

8. Druskat, V.U., Wheeler, J.V.: Managing from the boundary: the effective leadership of self-managing work teams. Acad. Manage. J. 46(4), 435-457 (2003)

9. Edmondson, A.: Psychological safety and learning behavior in work teams. Adm. Sci. Q. 44(2), 350-383 (1999)

10. Glaser, B.G., Strauss, A.L.: Discovery of Grounded Theory: Strategies for Qualitative Research. Routledge, Abingdon (2017)

11. Gren, L.: Psychological group processes when building agile software development teams. Ph.D. thesis, University of Gothenburgh (2017)

12. Gren, L., Torkar, R., Feldt, R.: Group development and group maturity when building agile teams: a qualitative and quantitative investigation at eight large companies. J. Syst. Softw. 124, 104-119 (2017)

13. Hersey, P., Blanchard, K.H., Natemeyer, W.E.: Situational leadership, perception, and the impact of power. Group Organ. Stud. 4(4), 418-428 (1979)

14. Hoda, R.: Self-organizing agile teams: a grounded theory. Ph.D. thesis, Victoria University of Wellington (2011)

15. Hoda, R., Noble, J., Marshall, S.: Developing a grounded theory to explain the practices of self-organizing agile teams. Empir. Softw. Eng. 17(6), 609-639 (2012)

16. Hoda, R., Noble, J., Marshall, S.: Self-organizing roles on agile software development teams. IEEE Trans. Softw. Eng. 39(3), 422-444 (2013)

17. Kozlowski, S.W.J., Watola, D.J., Jensen, J.M., Kim, B.H., Botero, I.C.: Developing adaptive teams: a theory of dynamic team leadership. Team effectiveness in complex organizations: cross-disciplinary perspectives and approaches, pp. 113-155 (2009)

18. Moe, N.B., Dingsøyr, T., Dybå, T.: A teamwork model for understanding an agile team: a case study of a scrum project. Inf. Softw. Technol. 52(5), 480-491 (2010)

19. Spiegler, S. V., Heinecke, C., Wagner, S.: Interview guidelines for "leadership gap in agile teams: how teams and scrum masters mature" (2018). https://doi.org/10. $5281 /$ zenodo. 2243113

20. Srivastava, P., Jain, S.: A leadership framework for distributed self-organized scrum teams. Team Perform. Manage.: Int. J. 23(5/6), 293-314 (2017)

21. Sutherland, J., Schwaber, K.: The scrum guide: the definitive guide to scrum: the rules of the game (2017). http://scrumguides.org/ 
22. Sutherland, J., Sutherland, J.J.: Scrum: the art of doing twice the work in half the time. Currency (2014)

23. Takeuchi, H., Nonaka, I.: The new new product development game. Harv. Bus. Rev. 64(1), 137-146 (1986)

24. Werder, K., Maedche, A.: Explaining the emergence of team agility: a complex adaptive systems perspective. Inf. Technol. People 31(3), 819-844 (2018)

Open Access This chapter is licensed under the terms of the Creative Commons Attribution 4.0 International License (http://creativecommons.org/licenses/by/4.0/), which permits use, sharing, adaptation, distribution and reproduction in any medium or format, as long as you give appropriate credit to the original author(s) and the source, provide a link to the Creative Commons license and indicate if changes were made.

The images or other third party material in this chapter are included in the chapter's Creative Commons license, unless indicated otherwise in a credit line to the material. If material is not included in the chapter's Creative Commons license and your intended use is not permitted by statutory regulation or exceeds the permitted use, you will need to obtain permission directly from the copyright holder.

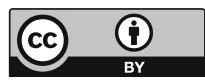

